Cite this: Phys. Chem. Chem. Phys., 2013,

\title{
Cyclodextrin stabilised emulsions and cyclodextrinosomes
}

15, 17903

Received 19th May 2013,

Accepted 27th August 2013

DOI: $10.1039 / \mathrm{c} 3 \mathrm{cp} 52116 \mathrm{~h}$

www.rsc.org/pccp

\author{
Baghali G. Mathapa and Vesselin N. Paunov*
}

\begin{abstract}
We report the preparation of $\mathrm{o} / \mathrm{w}$ emulsions stabilised by microcrystals of cyclodextrin-oil inclusion complexes. The inclusion complexes are formed by threading cyclodextrins from the aqueous phase on $n$-tetradecane or silicone oil molecules from the emulsion drop surface which grow further into microrods and microplatelets depending on the type of cyclodextrin (CD) used. These microcrystals remain attached on the surface of the emulsion drops and form densely packed layers which resemble Pickering emulsions. The novelty of this emulsion stabilisation mechanism is that molecularly dissolved cyclodextrin from the continuous aqueous phase is assembled into colloid particles directly onto the emulsion drop surface, i.e. molecular adsorption leads to effective Pickering stabilisation. The $\beta$-CD stabilised tetradecane-in-water emulsions were so stable that we used this system as a template for preparation of cyclodextrinosomes. These structures were produced solely through formation of cyclodextrin-oil inclusion complexes and their assembly into a crystalline phase on the drop surface retained its stability after the removal of the core oil. The structures of CD-stabilised tetradecane-in-water emulsions were characterised using optical microscopy, fluorescence microscopy, cross-polarised light microscopy and WETSEM while the cyclodextrinosomes were characterised by SEM. We also report the preparation of CD-stabilised emulsions with a range of other oils, including tricaprylin, silicone oil, isopropyl myristate and sunflower oil. We studied the effect of the salt concentration in the aqueous phase, the type of CD and the oil volume fraction on the type of emulsion formed. The CD-stabilised emulsions can be applied in a range of surfactant-free formulations with possible applications in cosmetics, home and personal care. Cyclodextrinosomes could find applications in pharmaceutical formulations as microencapsulation and drug delivery vehicles.
\end{abstract}

\section{Introduction}

Surfactants and polymers are routinely used as emulsifiers which adsorb at the oil-water interface and delay emulsion breakdown by lowering the interfacial tension and inducing repulsive interactions between the emulsion droplets. ${ }^{1,2}$ However, some low molecular weight surfactant emulsifiers can have detrimental effects, in particular when brought into contact with living matter for health and body care applications ${ }^{3,4}$ while others can be potentially hazardous for the environment, which has caused regulatory concern. Over the last decade, there has been an increased interest in replacement of surfactants with other emulsifiers which led to an exponential growth in research on Pickering emulsions, where solid colloid particles are used as emulsion stabilising agents. Colloidal particles adsorb irreversibly at the oil-water interface thereby giving

Surfactant and Colloid Group, Department of Chemistry, The University of Hull, Hull, HU6 7RX, UK. E-mail: V.N.Paunov@hull.ac.uk; Fax: +44 (0)1482 466410; Tel: +44 (0)1482 465660 more stable emulsions compared to emulsions from surfactants. The energy of the particle attachment to the oil-water interface is related to its three-phase contact angle $\theta$ at the oil-water interface and the oil-water interfacial tension. ${ }^{5-7}$ Various types of colloidal particles with different size, shape and surface chemistry have been studied as emulsifiers in Pickering emulsions ${ }^{8}$ for example; partially hydrophobised silica, ${ }^{9}$ silica, ${ }^{7}$ hydroxide particles. ${ }^{10,11}$ In addition, rod-like particles have been investigated for their ability to stabilize emulsions. Tzoumaki et al. ${ }^{8}$ investigated $\mathrm{o} / \mathrm{w}$ emulsions stabilized by chitin nanocrystal particles while Paunov et al. ${ }^{12}$ used modified calcium carbonate and spray-dried protein microparticles as emulsion stabilisers. Colloid particles with high aspect ratios are particularly efficient in stabilization of emulsions because they increase effective droplet coverage and if they are flexible they are able to intertwine when adsorbed at liquid interfaces. As a result, rod-shaped anisotropic particles typically out-perform equivalent spherical solid particles as emulsion stabilizers. ${ }^{13}$

Cyclodextrins (CDs) can be attractive alternative emulsion stabilisers with potential use in food, pharmaceutical and skin 
care due to their host-guest inclusion complex ability. CDs are biocompatible and nontoxic and previous studies have shown that CDs can form surface active complexes at the o/w interfaces that can stabilize emulsions. For example, Shimada et $a{ }^{14}{ }^{14}$ stabilised o/w emulsions using triglycerides as the oil phase, which has been emulsified with aqueous solutions of $\alpha$-CD and $\beta$-CD. The authors also studied the influence of $\alpha$-CD and $\beta$-CD on soybean $\mathrm{o} / \mathrm{w}$ interfacial tension. CDs did not change the surface tension of water alone but decreased the $\mathrm{o} / \mathrm{w}$ interfacial tension with the increase of their concentration. They reasoned that a partial inclusion complex was formed at the $\mathrm{o} / \mathrm{w}$ interface by CDs interacting with one fatty acid chain of the triglycerides. This results in a surface active complex of the $\mathrm{CD}$ with the triglyceride where the $\mathrm{CD}$ is being preferentially orientated towards the aqueous phase while the other two fatty acid chains in the complex are oriented towards the oil phase. ${ }^{15}$ It has also been reported that CDs thread along long polymer chains of suitable geometry to form microrods. Several research groups have shown that these self-assembled microrods can be obtained from CDs and different types of polymers. For example, Cheng et al. studied the threading of $\alpha$-CD on polyethyleniminepoly(ethylene glycol), ${ }^{16} \mathrm{Tu}$ et $a .^{17}$ reported the threading of $\alpha$-CD on poly(ethylene oxide)- $b-N$-isopropylacrylamide. $\mathrm{Wu}$ et $a .^{18}$ have reported micrometer-sized rod-like structures formed between $\beta$-CD and 2-phenyl-5-(4-diphenyl)1,3,4-oxadiazole. Lv et $a l^{19}$ reported thermo-sensitive amphiphilic supramolecular assembly based on the cyclodextrin inclusion complex.

So far, only few papers have been published discussing emulsions stabilised by CD inclusion complexes. Inoue et al. have reported the preparation and the characterization of $n$-alkane/water emulsions stabilised by CDs. They used $n$-octane, $n$-dodecane and $n$-hexadecane as the oil phase and investigated the emulsifying ability of $\alpha$-, $\beta$ - and $\gamma$-CD. These authors reported that at low CD concentrations, the CD complexes formed showed some surface activity but could not form stable emulsions. However, at high CD concentrations, the CD precipitated at the $\mathrm{o} / \mathrm{w}$ interface which the authors interpreted as a solid stabilised emulsion. They reported that the most stable emulsion was formed by $\beta$-CD complexes. ${ }^{20}$ These authors compared the stabilities of the emulsions from the three CDs by measuring the contact angle of the precipitates. They reported that all the three CD precipitates showed contact angles less than $90^{\circ}$ in the following order: $\beta$-CD $>\gamma$-CD $\gg \alpha$-CD. It is well known that particles with contact angles close to $90^{\circ}$ are most strongly adsorbed at the $\mathrm{o} / \mathrm{w}$ interface. Therefore, this gives an indication why $\beta$-CD-oil precipitates showed a better stabilizing effect than their $\gamma$-CD and $\alpha$-CD equivalents. The same authors have also studied the emulsifying ability of $\beta$-CD for common oils (squalane, soyabean and liquid paraffin) used in pharmaceuticals and cosmetics as well as edible oils such as fish oil. They reported that only $\mathrm{o} / \mathrm{w}$ emulsions were formed when using pure $\beta$-CD but upon using triacetyl- $\beta-C D$, tripropanoyl- $\beta-C D$ or tributanoyl- $\beta-C D$ they obtained w/o emulsion. 1,21 $^{2}$

Despite the recent efforts made in using CD-based microparticles as promising candidates for surfactant-free emulsion stabilization, ${ }^{30}$ no connection between the size and morphology of the CD-precipitates and their influence on the stability of the emulsions has been established so far. In this paper we demonstrate how the size and the shape of the CD-oil microcrystals depend on the CD used. Our efforts are directed towards highlighting the effect of the CD-oil IC particle size on its ability to form Pickering emulsion in addition to the effect of the particle contact angle discussed earlier. Although many authors emphasise that rod-shaped particles are better Pickering emulsifiers than spherical particles alone, no literature is available at the moment that links the stability of CD-stabilized emulsions to the shape of the CD inclusion complexes. In addition, we found that the shell of CD-oil microparticles around the o/w emulsion droplets is so stable that it allows the oil core to be removed thus yielding colloidosomes which could be used for encapsulation of actives. Such "cyclodextrinosomes" have not been reported before, therefore the spontaneous formation of biocompatible CD-based microcapsules would increase the use of CDs in a wide range of industrial products. Fig. 1 shows the schematic of forming CD Pickering emulsions and the subsequent fabrication steps for cyclodextrinosomes.

\section{Experimental}

\section{Materials}

Water was purified by passing through a reverse osmosis unit and then a Milli-Q ${ }^{\circledR}$ system. $\alpha$-CD and $\beta$-CD were sourced from Sigma and used without further purification. Tetradecane (99\%), isopropyl myristate (98\%) and tricaprylin (99\%) all from

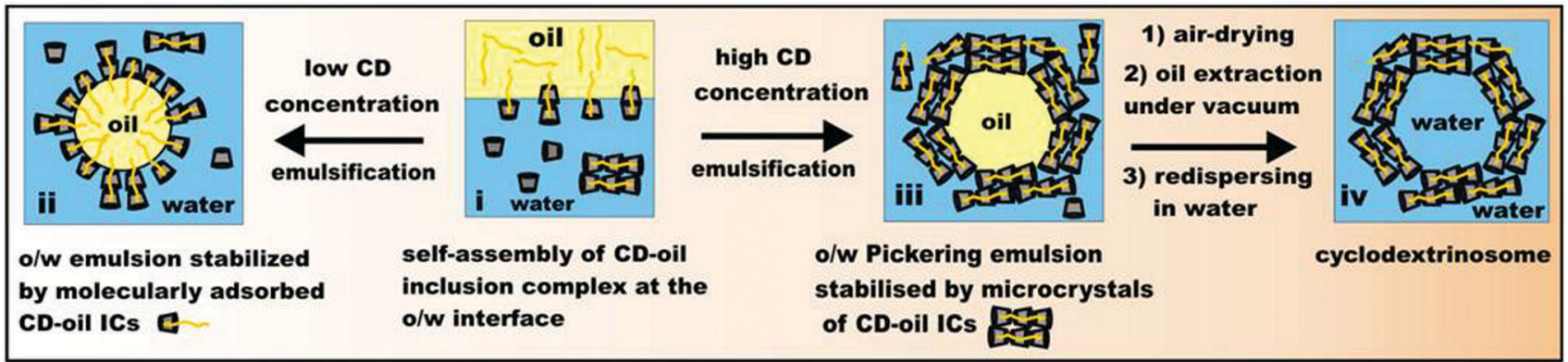

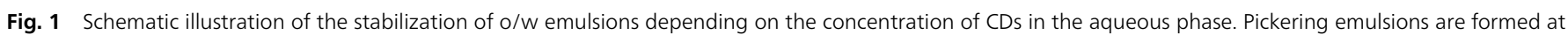
high CD concentration and can further be treated to yield novel CD colloidosomes. 
Sigma, were passed twice through chromatographic alumina (0.063-0.200 nm, Merck) to capture polar impurities before use.

$\mathrm{NaCl}$ (99\%) was purchased from Sigma. Low viscosity silicone oil (CP20) was sourced from Dow Corning and used without further purification. Sunflower oil was purchased from a local supermarket. Nile Red (98\%) from Sigma was used as received.

\section{Characterisation methods}

Optical microscopy. The morphology and the crystalline properties of the CD-tetradecane IC microrods were examined using an Olympus BX 51 optical microscope (Olympus, Japan) and the images were captured using a DP 70 Olympus digital camera (Japan) using Image Pro Plus ${ }^{\circledR}$ software (USA). Crosspolarisers were used in some of the experiments to determine the crystallinity of the CD-oil precipitates.

Scanning electron microscopy (SEM). The CD-oil IC crystalline samples, dispersed in Milli-Q water, were deposited on a $(1 \mathrm{~cm} \times 1 \mathrm{~cm})$ glass plate and air dried. After gold-sputtering under high vacuum, the sample was mounted on a SEM sample stub and viewed using a Zeiss EVO 60 SEM with $\mathrm{LaB}_{6}$ filament.

We used QX-102 capsules (Quantomix Ltd) for WETSEM emulsion characterisations. The QX-102 capsules consisting of a liquid dish and a sealing stub can be used for imaging various wet samples. Some of the emulsion samples were imaged with WETSEM which included placing a small drop of emulsion in a vacuum tight capsule, which allowed performing SEM imaging without removal of the aqueous phase as discussed in the following section.

\section{Results and discussion}

\section{O/W emulsions stabilised by poly(pseudo) rotaxanes from tetradecane $\mathrm{CD}$ inclusion complexes}

We prepared o/w emulsions stabilized by $\alpha$-CD and $\beta$-CD-based microcrystals which were formed in situ after emulsification of the oil ( $n$-tetradecane) in water. We studied the efficiency of these microcrystals as Pickering emulsion stabilisers in relation to their morphology and size. It has been reported that microrod particles offer a better Pickering stabilisation effect than equivalent spherical particles. ${ }^{31,32}$ In our experiments, we kept the CD concentration constant $(10 \mathrm{mM})$ but varied the total oil volume fraction $\left(\Phi_{\mathrm{o}}\right)$ between 0.01 and 0.8 . The oilwater mixture was then homogenised using an UltraTurrax ${ }^{\circledR}$ T25 rotor-stator device fitted with a S25N18G stainless steel shaft (IKA Germany) operating at $11000 \mathrm{rpm}$ for a period of 20 seconds.

At very small oil volume fractions we obtained only precipitates at the bottom of the sample tubes. This was observed for both $\alpha$-CD and $\beta$-CD. However, larger amounts of these microcrystals were formed in $\alpha$-CD solution compared to systems involving $\beta$-CD at the same oil volume fraction.

We found out that when $10 \mu \mathrm{L}$ of tetradecane was added to $10 \mathrm{~mL}$ of the $10 \mathrm{mM} \mathrm{CD}$ with subsequent emulsification, only microrods were obtained as shown in Fig. 2. The microrods from $\alpha$-CD-tetradecane were longer than $100 \mu \mathrm{m}$ whereas the
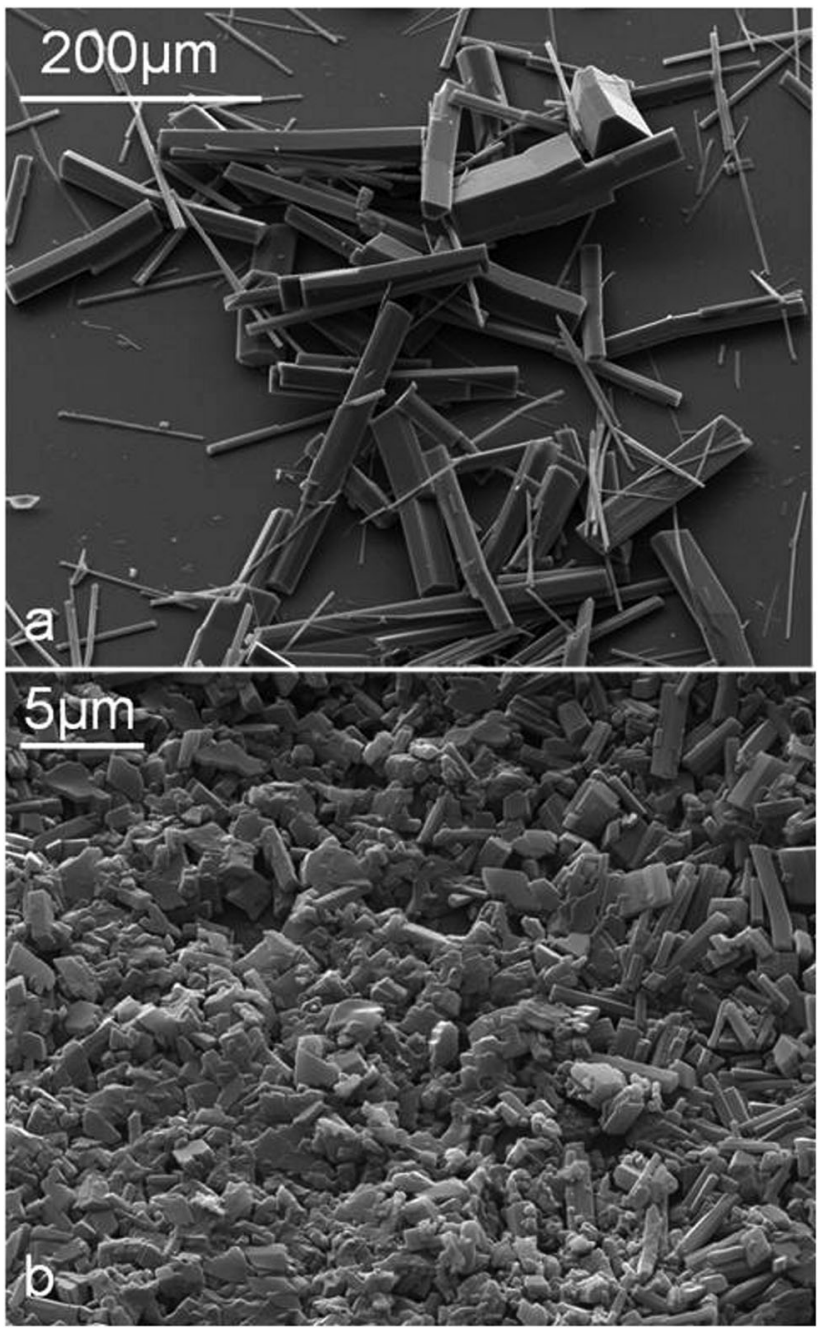

Fig. 2 SEM images of microrods prepared from $10 \mathrm{~mL}$ of $10 \mathrm{mM}$ aqueous CDs in the presence of $10 \mu \mathrm{L}$ of $n$-tetradecane. (a) with $\alpha-C D$; (b) with $\beta$-CD.

microcrystals from $\beta$-CD-tetradecane were much shorter $(<10 \mu \mathrm{m})$. We observed the morphology of the emulsion droplets using an optical microscope, which showed an enriched layer of microrods around the oil droplets and also the appearance of some microrods forming a 3D network in the aqueous phase around the droplets. Fig. 3 and 5 show typical emulsion droplets covered by CD-oil IC microrods. The microrods were accumulated around the oil droplets thereby forming a protective shell against droplet coalescence which stabilises the emulsion. Note that this entangled network formed by the microrods in the continuous phase has the potential to structure the media around the drops which could additionally slow down their coalescence. $^{22-24}$ The emulsion volume fraction decreased with the decrease of the oil volume fraction, while the formation of CD-tetradecane microrods in the sample bottom layer increased.

We characterised both the bottom and the top layer of the emulsified systems. The top layer of the dispersions contained primarily droplets stabilized by shells of microrods as shown in Fig. 3 and 5. 


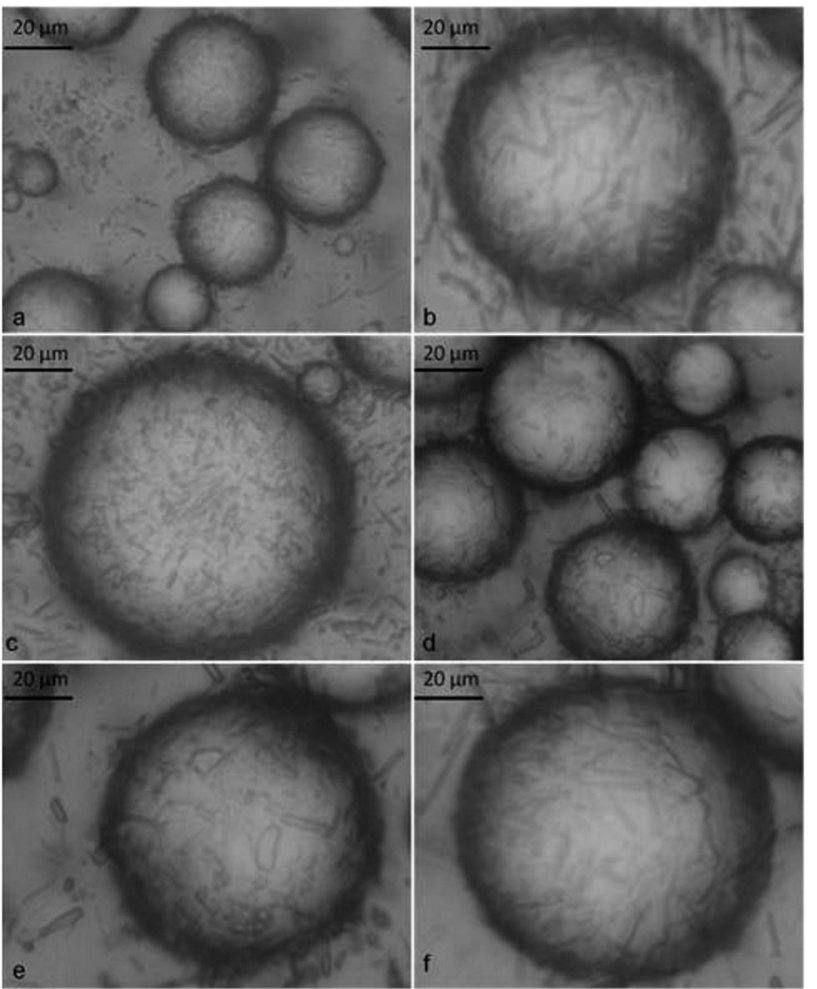

Fig. 3 Optical micrographs of o/w emulsions stabilised by $\alpha$-CD-tetradecane inclusion complexes. All emulsions were prepared from $10 \mathrm{mM} \alpha-\mathrm{CD}$ at different tetradecane volume fractions $\left(\Phi_{\circ}\right)$ : (a)-(c) $\Phi_{\circ}=0.1$ and $(\mathrm{d})-(\mathrm{f}) \Phi_{\mathrm{o}}=0.6$ taken 3 days after emulsification.

The $\alpha$-CD-stabilised system contained fewer emulsion droplets surrounded by many long microrods at the bottom layer as shown in Fig. $7 \mathrm{a}$ and $\mathrm{b}$. The $\beta$-CD-stabilised emulsions contained densely packed layers of small microparticles around the oil droplets (see Fig. 5b-d). We used cross-polarized light microscopy to illustrate that the microrods were concentrated around the oil droplets. As seen in Fig. 4, most of the birefringence was found around the droplets which confirmed that the microrods were formed only at the oil-water interface and not within the oil droplets. We discovered that smoother emulsion droplets were obtained as the oil volume fraction was increased in the $\beta$-CD stabilized emulsions. For example, at $\Phi_{\mathrm{o}}=0.1$, all droplets observed showed rough surfaces due to $\beta$-CD-tetradecane microcrystal formation even at low magnification as shown in Fig. 5b. Observations at higher magnification revealed that the drop surface is densely covered with these microparticles.

When we increased the oil volume fraction, only a few emulsion droplets with rough surface were observed among a much larger number of smooth emulsion droplets as shown in Fig. $6 \mathrm{a}$ at $\Phi_{\mathrm{o}}=0.5$. At $\Phi_{\mathrm{o}}=0.6$, we observed only droplets with smooth surfaces. A closer look at the droplet surface showed that they were covered with a dense multi-layer of paste like material (Fig. 6d). This suggests that finer particles were formed on the drop surface with the increase of the oil volume fraction.

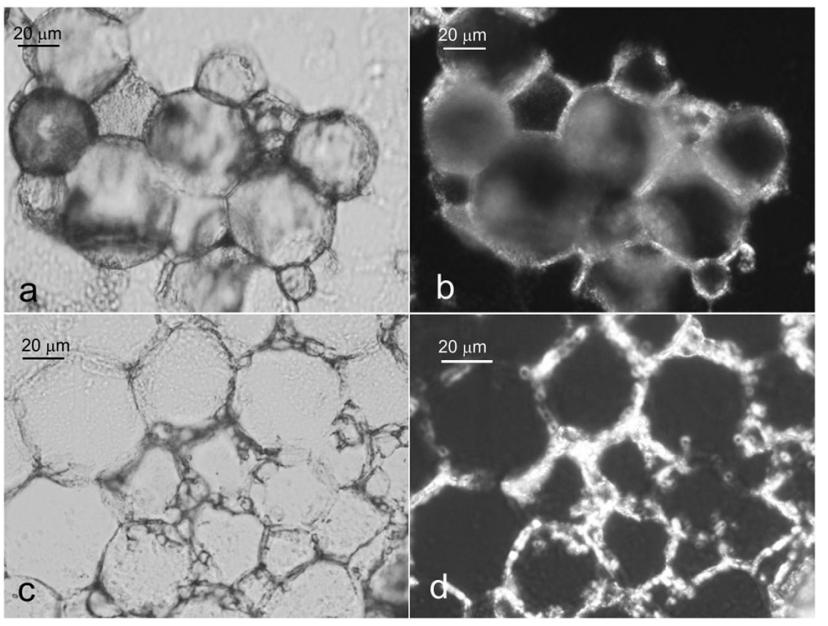

Fig. 4 Optical micrographs of o/w emulsions stabilised by $\alpha$-CD-tetradecane inclusion complexes. Emulsions were prepared from $10 \mathrm{mM} \alpha-\mathrm{CD}$ with the tetradecane volume fraction $\Phi_{\mathrm{O}}=0.6$. (a) The transmitted light image of the wet sample; (b) the cross-polarized light image; (c) the transmitted light image and (d) the cross-polarized light image of the emulsion sample after being airdried overnight.

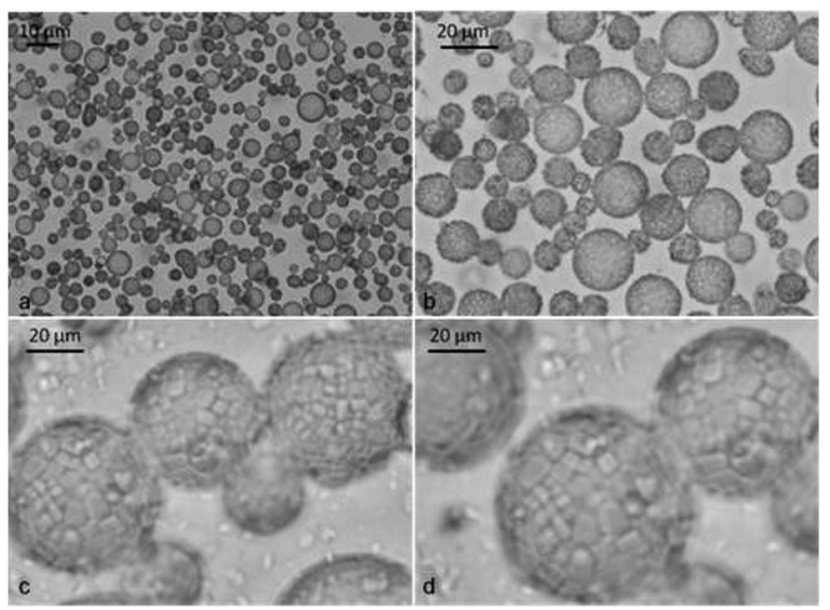

Fig. 5 Optical micrographs of o/w emulsions stabilised by $\beta-C D$-tetradecane inclusion complexes. Emulsions were prepared from $10 \mathrm{mM} \beta-\mathrm{CD}$ with tetradecane at different volume fractions $\left(\Phi_{\mathrm{o}}\right)$. (a)-(d) Optical micrographs of the emulsion sample at $\Phi_{\mathrm{o}}=0.1$ taken 3 days after emulsification showing densely packed microparticles around the droplet at different magnifications.

\section{SEM analysis}

The packing and ordering of the particles at the oil-water interface was investigated by using both WETSEM and SEM. For the WETSEM study, a sample of emulsion from $\Phi_{\mathrm{o}}=0.3$ was placed in a Quantum X-102 sample cell (Fig. 8a and b) which was then tightly sealed. The sample cell was then mounted on a sample holder and placed in the SEM vacuum chamber. The sample was then observed using a Zeiss EVO 60 SEM in backscattering mode. The images showed some white spherical particles (o/w droplets) due to electron scattering against a dark background of water. In addition, we observed some elongated structures due to partially coalesced emulsion 

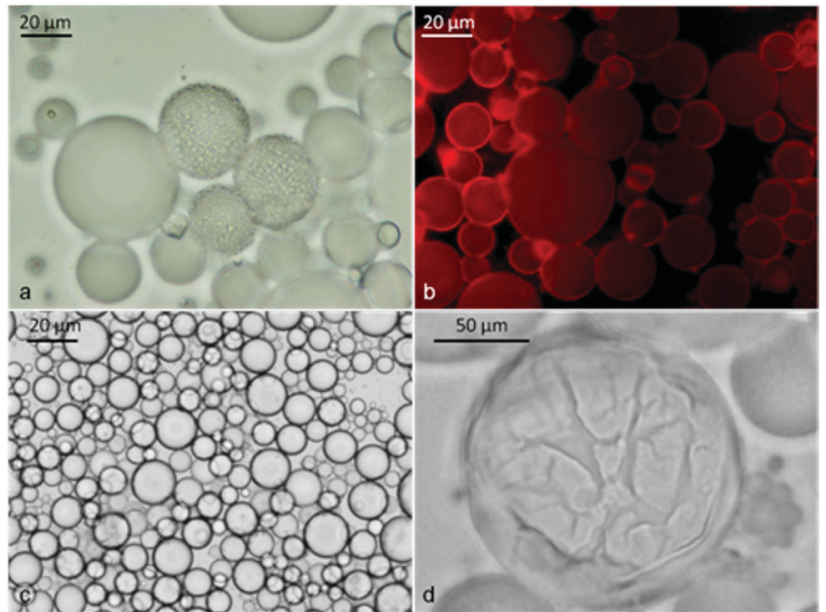

Fig. 6 Micrographs of tetradecane-in-water emulsions stabilized by $\beta-C D /$ $n$-tetradecane inclusion complexes: (a) $\Phi_{\mathrm{o}}=0.5$; (b) the fluorescence microscopy image of freshly prepared emulsion with an oil phase doped with Nile Red and observed using a TRITC filter set. The image shows that the oil was the dispersed phase. (c) and (d) The micrograph from the sample with $\Phi_{\mathrm{o}}=0.6$ taken 14 days after preparation at different magnifications. (d) The optical micrograph shows the presence of a densely packed surface layer with "paste-like" appearance, stabilizing the oil droplets against coalescence.

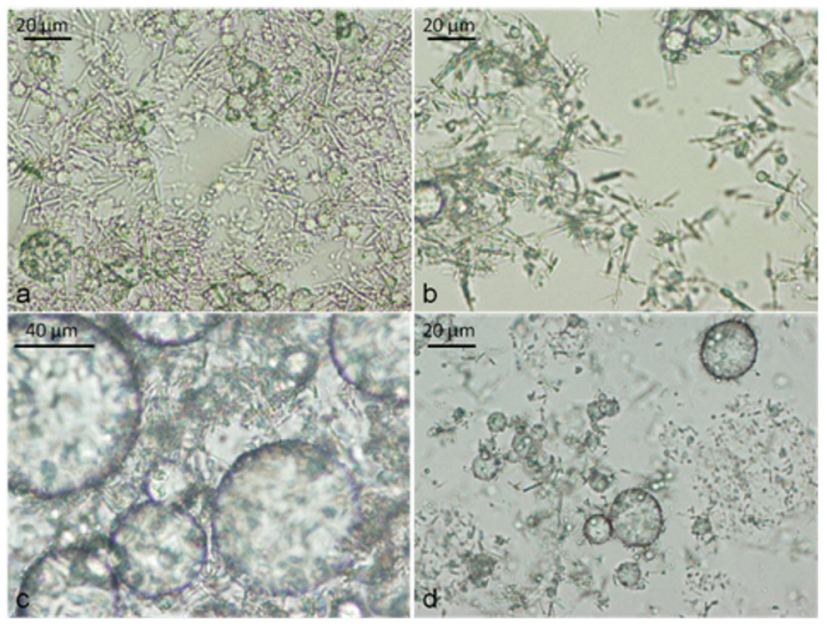

Fig. 7 Micrographs showing the presence of long CD-oil IC microrods from samples prepared from $10 \mathrm{mM} \alpha-C D$ with tetradecane oil at different oil volume fraction, $\Phi_{\mathrm{o}}$. (a) At $\Phi_{\mathrm{o}}=0.02$ (precipitate); (b) at $\Phi_{\mathrm{o}}=0.05$ (bottom layer); (c) at $\Phi_{\mathrm{o}}=0.08$ (top layer); (d) at $\Phi_{\mathrm{o}}=0.08$ (precipitate).

droplets (Fig. 8c). We also observed typical spherical structures completely coated with the CD-oil IC microcrystals (Fig. 8d). Their stability prompted us to deposit and air-dry the same emulsion on a glass slide $(\sim 1 \mathrm{~cm} \times 1 \mathrm{~cm})$ so that we can examine them directly using a conventional SEM. After airdrying, the samples were coated under vacuum with gold and viewed under a Zeiss EVO 60 SEM. This experiment confirmed that the spherical structures observed under an optical microscope and WETSEM were Pickering o/w emulsion droplets. For a $\beta$-CD stabilised system, we were able to observe a crack-opened shell with around 2-3 layers of the stabilizing microcrystals of the $\beta$-CD-tetradecane inclusion complex (Fig. 9c and d).

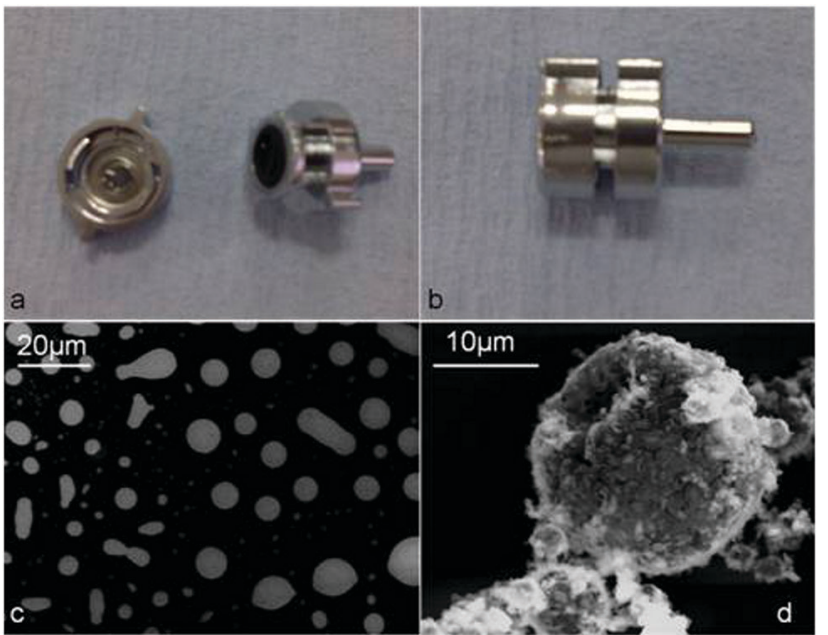

Fig. 8 Optical images of (a) an open WETSEM sample cell; (b) a closed WETSEM sample cell; (c) WETSEM micrographs for $\beta$-CD-tetradecane stabilized emulsions $\left(\Phi_{\mathrm{o}}=0.3\right)$ and $(\mathrm{d})$ a particle coated oil droplet.

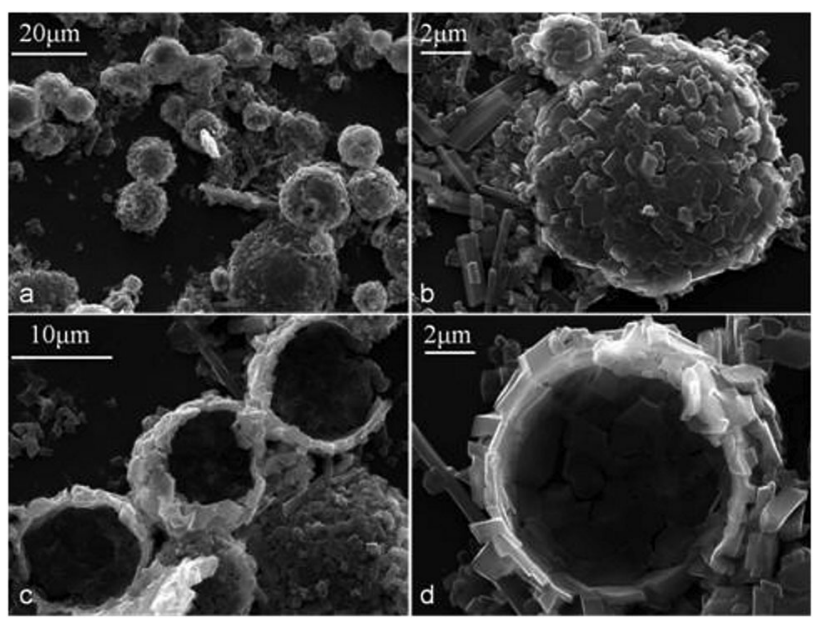

Fig. $9 \beta$-CD-tetradecane $\left(\Phi_{\mathrm{o}}=0.3\right)$ colloidosomes: (a) intact colloidosomes of $\beta$ CD-tetradecane IC microcrystals after the evaporation of the oil cores; (b) the larger magnification image of such cylcodextrinosome lying on the surface of microscope slide; (c) and (d) crack-open hollow colloidosomes of $\beta$-CD-tetradecane ICS.

The crack-opened membranes revealed that the first layer of particles was mostly lying flat on the oil-droplet surface while the subsequent layers were oriented randomly (see Fig. 9d). From this experiment we have for the first time confirmed that the size of the formed CD-oil inclusion complex particles is very critical for imparting stability to Pickering emulsions.

As shown in Fig. 9a and b, only small particles were found attached to the surface of the droplets. Contrarily in the same Fig. 9, larger and longer CD-oil IC microcrystals were found only lying between droplets on the surface of the microscope slide not on the surface of the templated droplets. When $\alpha$-CD stabilised emulsion of the same oil composition $\left(\Phi_{\mathrm{o}}=0.3\right)$ was air-dried and observed with SEM, only collapsed structures were observed as shown in Fig. 10a-d. The $\alpha$-CD-tetradecane stabilised emulsion system was characterised by larger and 


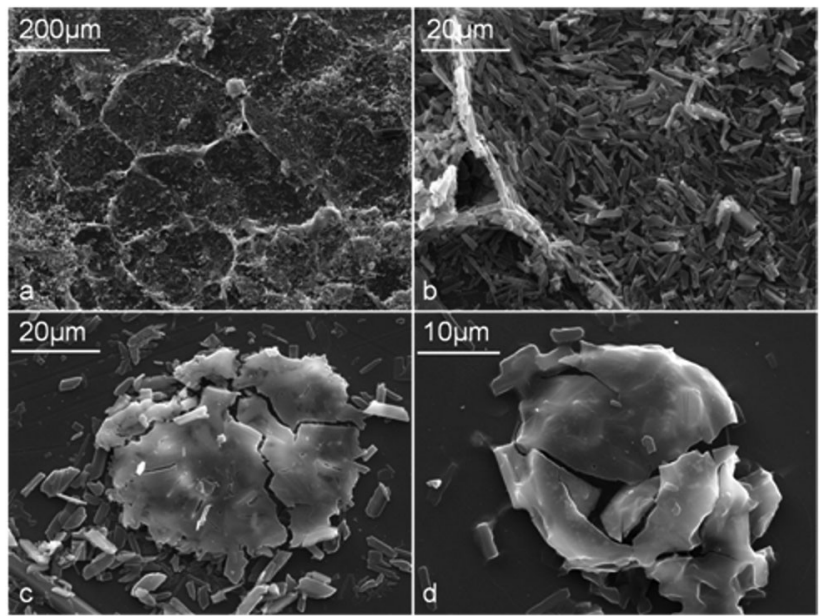

Fig. $10 \alpha$-CD-tetradecane $\left(\Phi_{\mathrm{o}}=0.3\right.$ ) colloidosomes: (a) collapsed colloidosomes of $\alpha$-CD-tetradecane microcrystals; (b) $\alpha$-CD-tetradecane inclusion complex particles from collapsed colloidosomes; (c) and (d) crushed smooth surface colloidosomes obtained from $\alpha$-CD-tetradecane stabilised emulsions $\left(\Phi_{\mathrm{o}}=0.3\right)$.

longer microcrystals of the IC and confirmed that larger microcrystals are not as effective stabilisers as the smaller ones. $\alpha$-CD-tetradecane IC microcrystals are long and rigid hence they cannot follow the curvature of the oil droplet or intertwine along the oil droplet and this leads to less tightly packed $\alpha$-CD particles at the $\mathrm{o} / \mathrm{w}$ interface resulting in weaker membranes. The latter were easily destroyed under vacuum while the tightly packed smaller $\beta$-CD-tetradecane particles formed shells which were firm enough to stand intact after the evaporation of the oil core in vacuum. Drying the emulsions and then subjecting them to vacuum to extract the core-oil yielded hollow colloidosomes $^{25,26}$ with the $\beta$-CD-tetradecane inclusion complex formed microcrystals forming the microcapsule wall as shown in Fig. 9c and d. The CD-inclusion complex particles are held together by mainly hydrogen bonding, therefore it is possible to use organic solvents such as $n$-hexane to extract the core-oil but there is also a possibility of de-threading which might lead to the collapse of these microcapsules. As a result, we envisage that the evaporation of the core-oil of CD-stabilised emulsions under vacuum would be the preferred method to use to form cyclodextrinosomes. We also air-dried $\alpha$-CD stabilised emulsions $\left(\Phi_{\mathrm{O}}=0.3\right)$ and removed the oil cores under vacuum but this produced collapsed microcapsules as revealed by the SEM images in Fig. 10.

This illustrates that the long $\alpha$-CD-tetradecane particles were not suitable for building strong microcapsule membranes compared to the ones from $\beta$-CD-tetradecane microcrystals. SEM imaging also confirmed the presence of microcapsules with smooth surfaces (Fig. 10d). Similar effects of formation of smooth polymer membranes have also been observed in other systems upon microencapsulation of oils. ${ }^{27}$

\section{Emulsion type}

We used the fluorescent dye staining method and conductivity measurements to assess the type of emulsion formed at different oil volume fractions. Using the dye method, we doped the oil phase with Nile Red before the emulsification. Nile Red is an oil soluble fluorescent dye which allowed us to localise the oil phase using the TRITC filter set. We prepared three emulsions stabilised with $\alpha$-CD $(10 \mathrm{mM})$ with different tetradecane volume fractions $\left(\Phi_{\mathrm{o}}\right)(0.08,0.3$ and 0.6$)$. In addition, for the sample with $\Phi_{\mathrm{o}}=0.6$, the aqueous phase was doped with Fluorescein $\left(10^{-5} \mathrm{M}\right)$ before emulsification and observed with a fluorescence microscope after the emulsion preparation. As can be seen in Fig. 11, all the emulsions were o/w. Even for significantly higher oil volume fractions $\left(\Phi_{\mathrm{o}}=0.6\right)$, the oil droplets formed the dispersed phase as shown by the green background of the fluorescein doped aqueous phase. This confirms the results of Inoue et $a .^{21}$ for similar CD-stabilised systems who only managed to form w/o emulsions by using triacylated $\beta-\mathrm{CD}$ as an emulsifier.

We also assessed the emulsion type by measuring the electrical conductivity of the emulsions immediately after emulsification. For this experiment, we used aqueous phases with $10 \mathrm{mM} \beta-\mathrm{CD}$, dissolved in $10 \mathrm{mM} \mathrm{NaCl}$ and $100 \mathrm{mM} \mathrm{NaCl}$, respectively. Emulsions were then prepared by varying the oil volume fraction $\Phi_{\mathrm{o}}$ and their conductance was measured immediately after emulsification (11000 rpm for $20 \mathrm{~s}$ ) using a Jenway 4510 digital conductivity meter. The total volume of the mixture was $10 \mathrm{~mL}$. No significant difference was observed irrespective of the negative surface charge at the pure oil-water interface. $^{28}$

Fig. 12 shows the gradual decrease in conductance of the emulsions with the increase of the oil volume fraction in the system which suggests that the type of the emulsion remains $\mathrm{o} / \mathrm{w}$ with an abrupt change in the conductance after $\Phi_{\mathrm{o}}=0.6$ which suggests that between $\Phi_{\mathrm{o}}=0.6$ and 0.8 , the emulsion

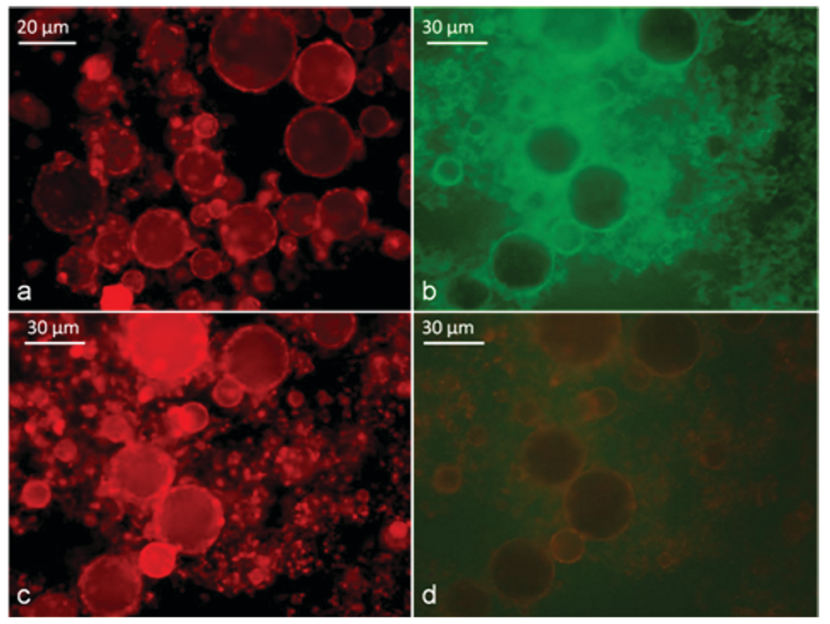

Fig. 11 Identification of the type of $\alpha-C D$ stabilised emulsion with tetradecane at different $\Phi_{\mathrm{o}}$ using doping with fluorescent dyes: (a) freshly prepared emulsion from $\Phi_{\mathrm{o}}=0.08$ with tetradecane initially doped with Nile Red before emulsification; sample was observed under TRITC filter sets. (b) Freshly prepared emulsion from $\Phi_{\mathrm{o}}=0.6$; tetradecane was initially doped with Nile Red while the aqueous phase was doped with fluorescein before emulsification; the sample was observed under FITC filter sets; (c) the same sample observed under TRITC filter sets and (d) with dual fluorescence TRITC-FITC filters sets. 


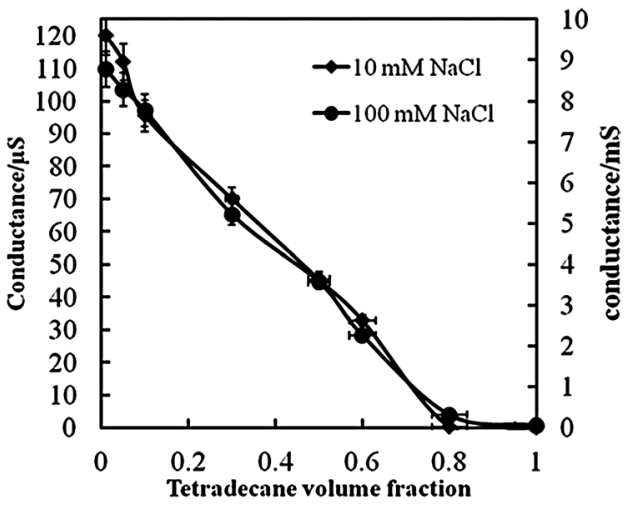

Fig. 12 Conductance of tetradecane-water emulsions stabilised by $10 \mathrm{mM}$ $\beta-C D$ in the aqueous phase at two different concentrations of $\mathrm{NaCl}$ as a function of the tetradecane volume fraction. Solid lines are guidelines to the eye. Error bars represent the standard deviation.

might be close to catastrophic phase inversion from $\mathrm{o} / \mathrm{w}$ to w/o. ${ }^{29}$ However, we were not able to observe w/o emulsion above this oil volume fraction. These results are in support of the fluorescence dye tests which showed that the emulsions were $\mathrm{o} / \mathrm{w}$.

\section{Emulsion stability experiments}

The stability of CD-stabilised emulsions against coalescence was assessed by monitoring the height of the emulsion layer above the clear aqueous phase (serum) as a function of time. We prepared $\alpha$-CD and $\beta$-CD (both $10 \mathrm{mM}$ ) stabilised emulsions with varying oil volume fraction $\left(\Phi_{\mathrm{o}}=0.01-0.8\right)$. We found that samples prepared from $\Phi_{\mathrm{o}}=0.6$ followed by $\Phi_{\mathrm{o}}=0.5$ (both for $\alpha$-CD and $\beta$-CD) exhibited remarkable stability against coalescence as shown in Fig. 13-15. However, after 4 weeks of storage at room temperature without shaking, almost all $\alpha$-CD stabilised emulsions phase-separated as shown in Fig. 14b, with the exception of the oil volume fraction $\Phi_{\mathrm{o}}=0.1$. In contrast, $\beta$-CDstabilised emulsions were still stable and the ones prepared from $\Phi_{\mathrm{o}}=0.6$ and 0.5 showed very little phase-separation even after six months. These results highlight the importance of the size of the microcrystals from CD-oil inclusion complexes with regard to their ability to stabilise emulsions. Furthermore, the rate of in situ formation of these microrods has some bearing on the stability of the emulsions. Formation of the small microcrystals leads to a better packed layer of them on the emulsion droplets and better stabilisation. On the other hand, long and heavy micro-rods are prone to sedimentation with poor droplet stabilisation. Comparing $\alpha$-CD and $\beta$-CD emulsions, we can see that after 24 hours of preparation, $\beta$-CDstabilised samples ( $\Phi_{\mathrm{o}}=0.01$ to 0.1 ) were turbid throughout the dispersions while $\alpha$-CD-stabilised samples with the same compositions had separated into three layers: emulsion, a clear region and the microcrystalline sediment at the bottom, while samples with $\Phi_{\mathrm{o}}=0.3$ and 0.5 separated into an emulsion top layer and an aqueous bottom layer. Samples with $\Phi_{\mathrm{o}}=0.5$, 0.6 and 0.8 for both $\alpha$-CD and $\beta$-CD stabilised systems showed similar behaviour. This suggests that $\beta$-CD formed

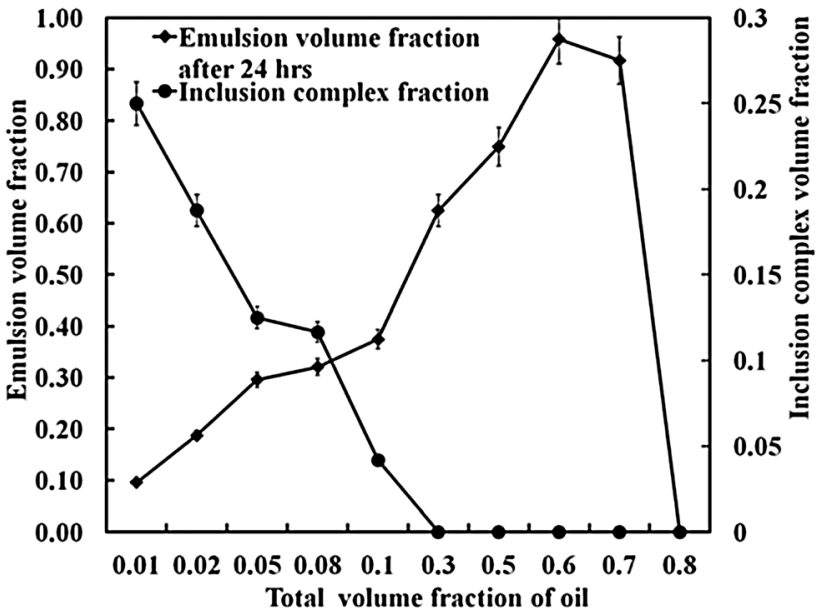

Fig. 13 Stability against coalescence of $\alpha-C D$ stabilised emulsions upon varying the tetradecane volume fraction. The total emulsion volume fraction was measured 24 hours after preparation. The other graph shows the volume fraction of the precipitated $\alpha$-CD-tetradecane microrods at the bottom of the sample tube 24 hours after emulsification (see the LHS axis).

small particles which can stay suspended in the continuous phase for a longer time. Few deposits were observed for the $\beta$-CD-stabilised systems even after 6 months. Fig. 2 shows that the $\alpha$-CD-tetradecane microcrystals are long $(\gg 20 \mu \mathrm{m})$, rodlike structures while $\beta$-CD microcrystals are much smaller $(<10 \mu \mathrm{m})$ and mostly cubic like.

The stability of Pickering emulsions are usually determined by the particle size, particle wettability, particle concentration, salt concentration and $\mathrm{pH} .{ }^{8}$ Inoue et al. ${ }^{21}$ reported that all the native $\operatorname{CDs}(\alpha, \beta$ and $\gamma$ ) formed inclusion complexes with $n$-alkanes that showed contact angles of the powder below $90^{\circ}$ with $\beta$-CD complexes having contact angles close to $90^{\circ}$ and $\alpha$-CD complexes having much lower contact angles. Such results show that the CD inclusion complex particles are hydrophilic and would stabilize o/w which was consistent with our results. In addition, particles with contact angles close to $90^{\circ}$ are more strongly adsorbed compared to more hydrophilic or more hydrophobic particles. Therefore it was not surprising that microcrystals of $\beta$-CD-tetradecane complexes with contact angle close to $90^{\circ}$ formed more stable Pickering emulsions than $\alpha$-CD stabilized emulsions.

We envisage that in addition to the influence of the particle contact angle, reported by Inoue et al., the smaller $\beta$-CD-tetradecane microparticles adsorb and tightly pack at the oil-water interface as shown in Fig. 5, 8 and 9. In addition, they are easily heaped up and aggregate around the oil droplets generating a steric barrier that prevents droplet coalescence and hence ensures effective emulsion stabilisation (see Fig. 5d, 9c and d). In contrast, long and rigid $\alpha$-CD-tetradecane microrods cannot effectively pack when adsorbed at the oil-water interface which increases the likelihood of exposure of bare oil patches on the drops surface leading to coalescence and instability.

Fig. 14a shows that with the reduction of the oil volume fraction in the system, the amount of the microrods formed increased drastically, suggesting that all of it was included in 


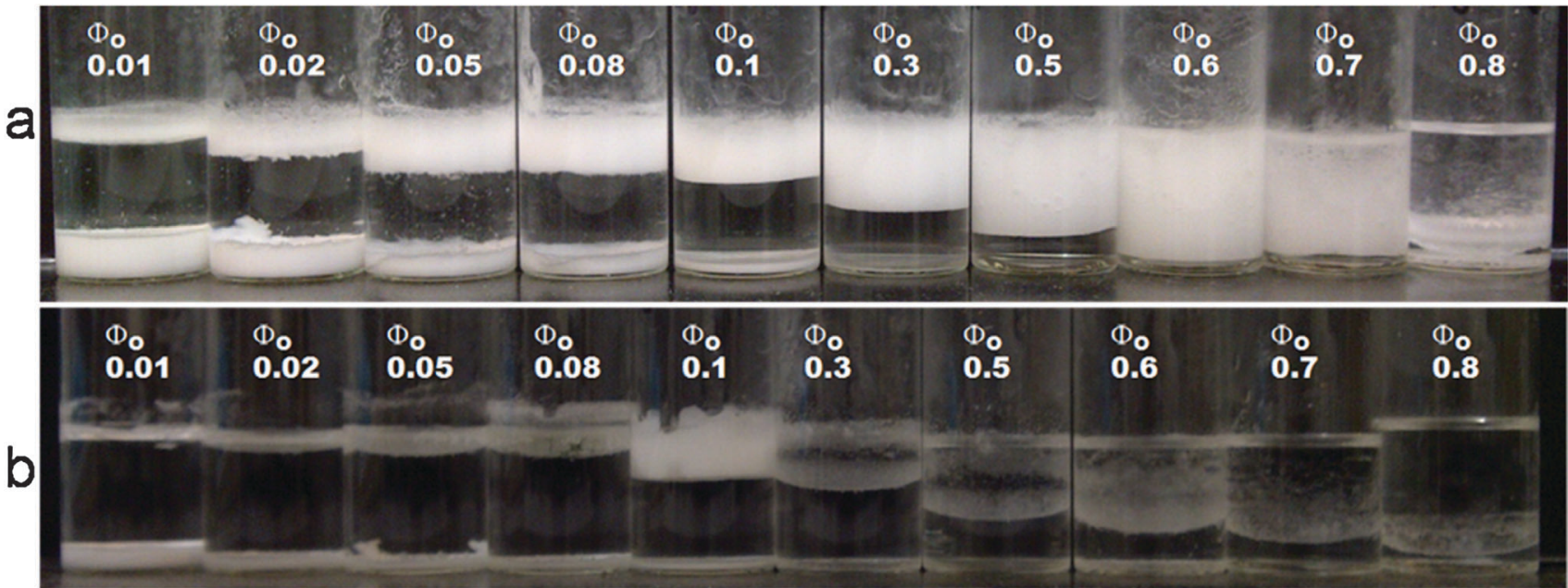

Fig. 14 Stability of $\alpha$-CD stabilized emulsions under varying tetradecane volume fractions. (a) Emulsions 24 hours after emulsification. Note the decrease in the amount of emulsions (top layer) and the increase in the amount of microrods as the volume fraction of the oil is reduced. The most stable emulsion was formed at $\Phi_{\mathrm{o}}=0.6$. (b) The emulsion phase separated after about 4 weeks except for $\Phi_{\mathrm{o}}=0.1$.

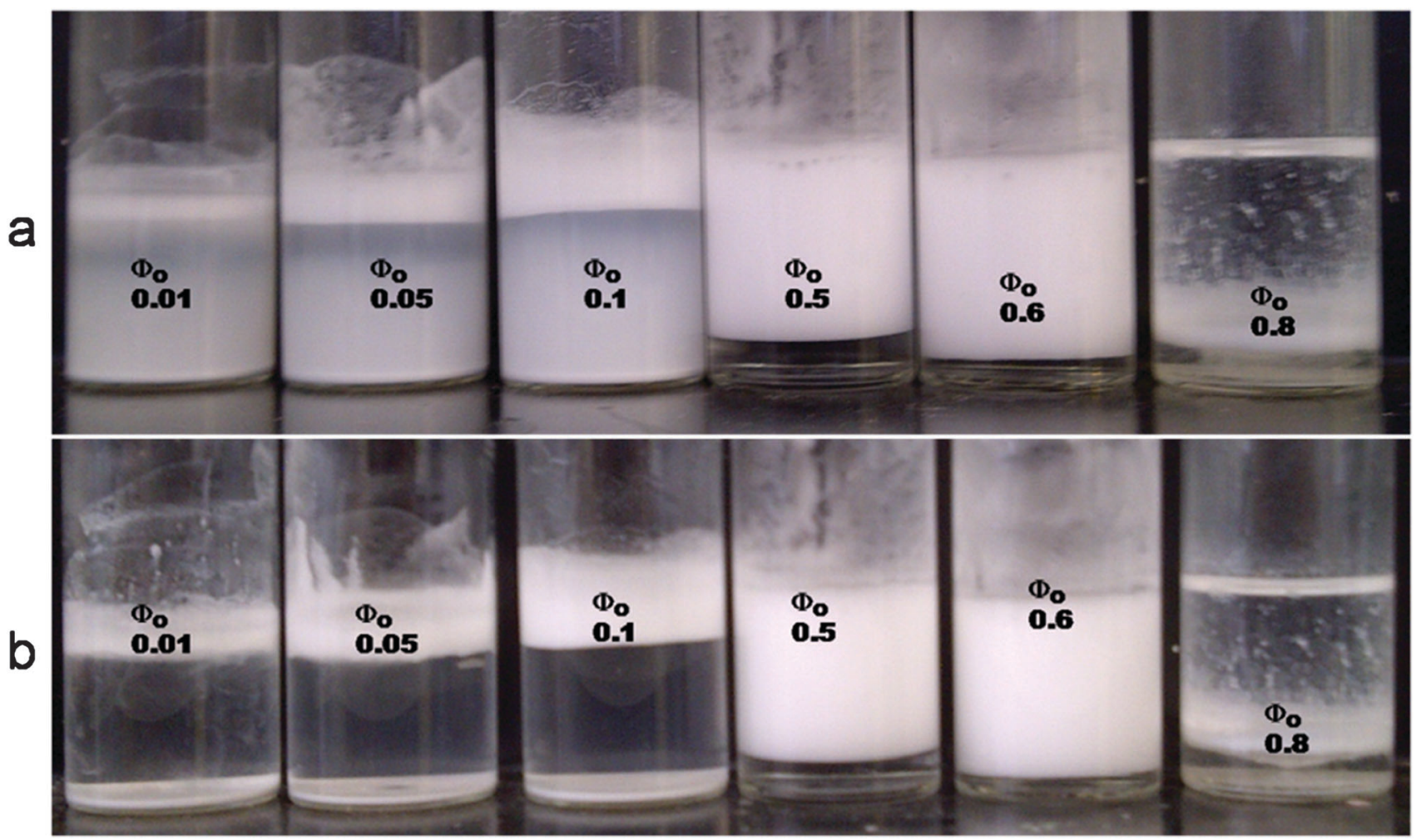

Fig. 15 Stability of $\beta-C D$ stabilized emulsions under varying tetradecane volume fractions. (a) Emulsions 48 hours after emulsification. Note the turbidity of the aqueous layer in the systems at low $\Phi_{\mathrm{o}}$ due to small microparticles which can stay suspended in the aqueous phase for a longer time. The most stable emulsion was formed at $\Phi_{\mathrm{o}}=0.6$. (b) The layers of creamed emulsion were still stable after 4 months.

the CD cavities, possibly by threading of multiple CD molecules per molecule of tetradecane. Since there were no oil droplets left to adsorb onto, the microrods instead sediment at the bottom of the sample tube. We confirmed this by preparing CD-tetradecane microrods by dispersing samples of $10 \mu \mathrm{L}$ tetradecane in $10 \mathrm{~mL}$ of $10 \mathrm{mM}$ CDs (see the microcrystals formed in Fig. 2).
Very stable $\mathrm{o} / \mathrm{w}$ emulsions were produced when particles were weakly flocculated by increasing the salt concentration, as also pointed out by other authors. ${ }^{7}$ The effect of $\mathrm{NaCl}$ on the stability of the $\beta$-CD stabilised o/w emulsion was investigated using $10 \mathrm{mM}$ and $100 \mathrm{mM} \mathrm{NaCl}$ and comparing to $\beta$-CDstabilised emulsions prepared with Milli-Q-water. The effect of $\mathrm{NaCl}$ on the stability of $\beta$-CD stabilized emulsions is shown 


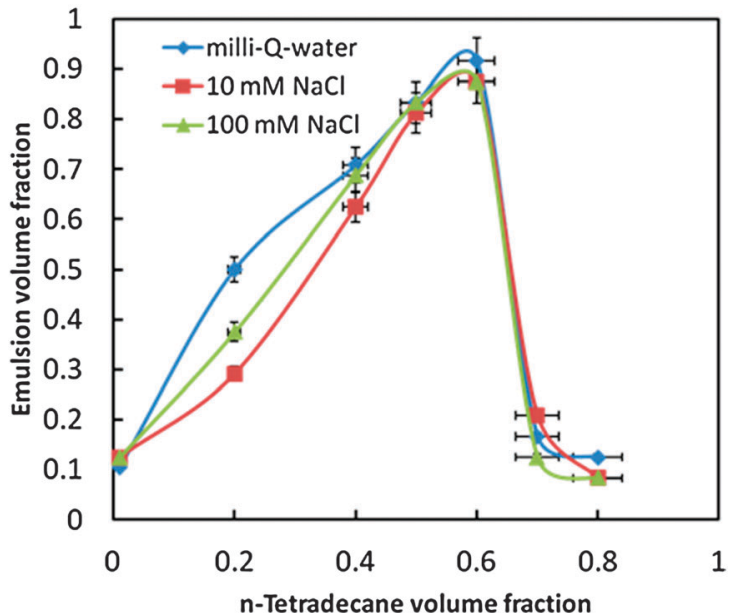

Fig. 16 Effect of $\mathrm{NaCl}$ on the stability of $\beta-\mathrm{CD}$ stabilised emulsions against creaming under varying tetradecane oil volume fractions. Measurements were carried out 3 days after emulsification.

in Fig. 16. The height of the emulsion layer was measured 3 days after emulsification to determine the emulsion fraction. We found that $\mathrm{NaCl}$ induced the precipitation of the microrods.

As shown in Fig. 17, for $\Phi_{\mathrm{o}}=0.01$ the emulsion prepared in the absence of $\mathrm{NaCl}$ was cloudy throughout 3 days after the emulsification while for $\Phi_{\mathrm{o}}=0.01$ in the presence of $\mathrm{NaCl}$, the dispersions were clear and phase separated. In addition, one can see that for $\Phi_{\mathrm{o}}=0.6$, the presence of high salt concentration led to a small phase separation (Fig. 17c).

\section{Water-in-oil emulsions stabilized by cyclodextrins}

We have also investigated the stability of w/o emulsions stabilized by CDs using the following oils; sunflower oil, tricaprilyn, squalane, isopropyl myristate and silicone oil. We used $10 \% \mathrm{v} / \mathrm{v}$ $(0.3 \mathrm{~mL})$ of aqueous solutions of $\alpha-\mathrm{CD}$, methyl- $\beta$-CD and $\gamma-\mathrm{CD}$ in $90 \% \mathrm{v} / \mathrm{v}(2.7 \mathrm{~mL})$ of each of the above named oils. The emulsions were prepared by emulsifying the biphasic layers using an Ultra Turrax T-25 rotor stator homogeniser fitted with an $8 \mathrm{~mm}$ stainless steel shaft rotating at $11000 \mathrm{rpm}$ for 15 seconds. The most stable w/o emulsions stabilized by CDs were obtained when silicone (viscosity $1000 \mathrm{cSt}$ ) was used as the continuous phase. Fig. 18 shows emulsions from different oils but the same $\% \mathrm{v} / \mathrm{v}$ in the presence of $0.1 \mathrm{M} \mathrm{NaCl}$. It can be clearly seen that after three days of their preparation, emulsions prepared from silicone were still stable while the majority of $\mathrm{w} / \mathrm{o}$ emulsions from the other oils were phase separated. It can also be noted that all CDs used produced stable emulsions with silicone oil of high viscosity (1000 cSt).

\section{Emulsion drop size distributions}

We measured the drop size of the emulsions prepared both in the presence and absence of $\mathrm{NaCl}$ by the linear intercept method using an Olympus BX 51 microscope connected to a DP 70 Olympus digital camera using Image Pro Plus software. Fig. 19 shows the average droplet size of $\beta$-CD stabilized emulsions from samples prepared in the presence and absence of $\mathrm{NaCl}$ at various tetradecane volume fractions. We were aiming to check the effect of surface charge at the oil-water interface on the formation of the CD-oil-complexes as it is well known that $\mathrm{OH}^{-}$adsorption on the emulsion drop surface can lead to negative surface charge. ${ }^{28}$ One can see that the drop size increases its sensitivity to the presence of $\mathrm{NaCl}$ at high tetradecane volume fractions. The origin of this effect is not clear at present and would need more thorough investigation which will be addressed in future publications.

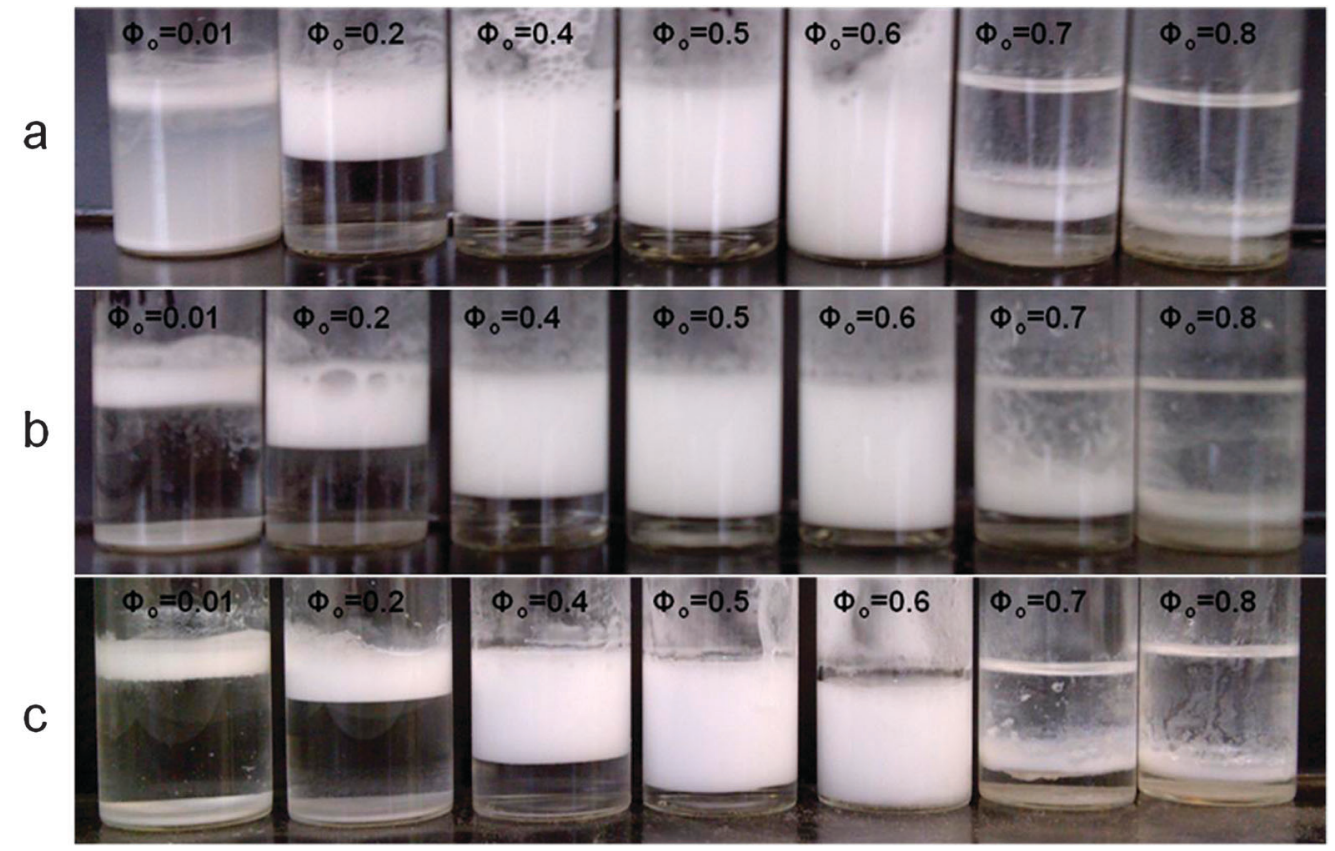

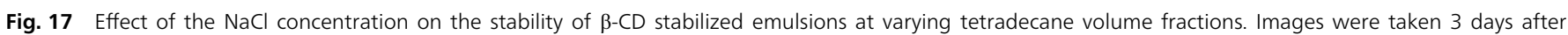

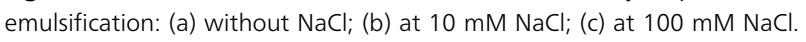



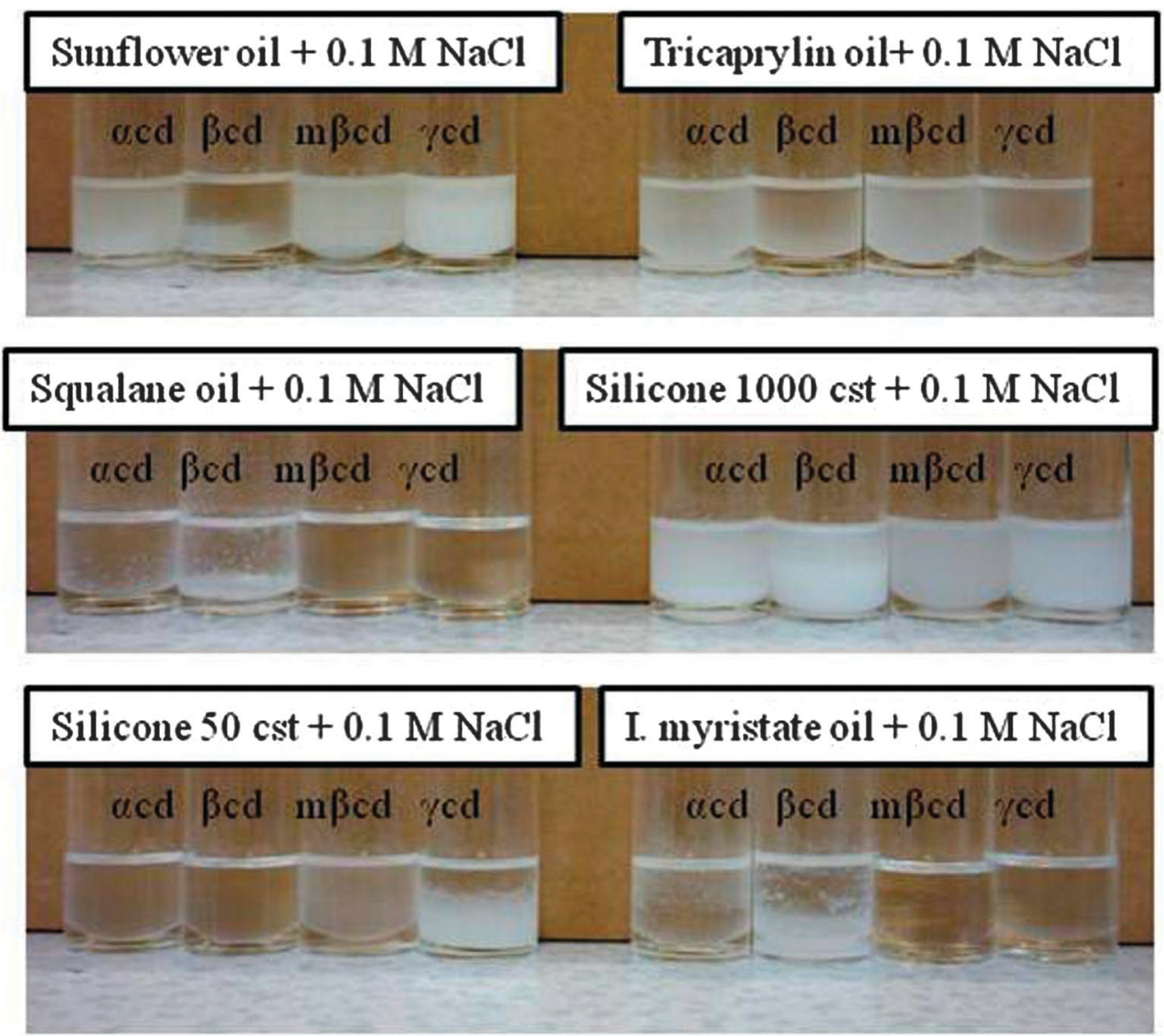

Fig. 18 Optical images of emulsions prepared from different oils and $0.1 \mathrm{M} \mathrm{NaCl}$ aqueous solution in the presence of four different types of cyclodextrin $(\alpha-C D, \beta-C D$, methyl- $\beta-C D, \gamma-C D)$. The images show the phase separation 3 days after the emulsion preparation.

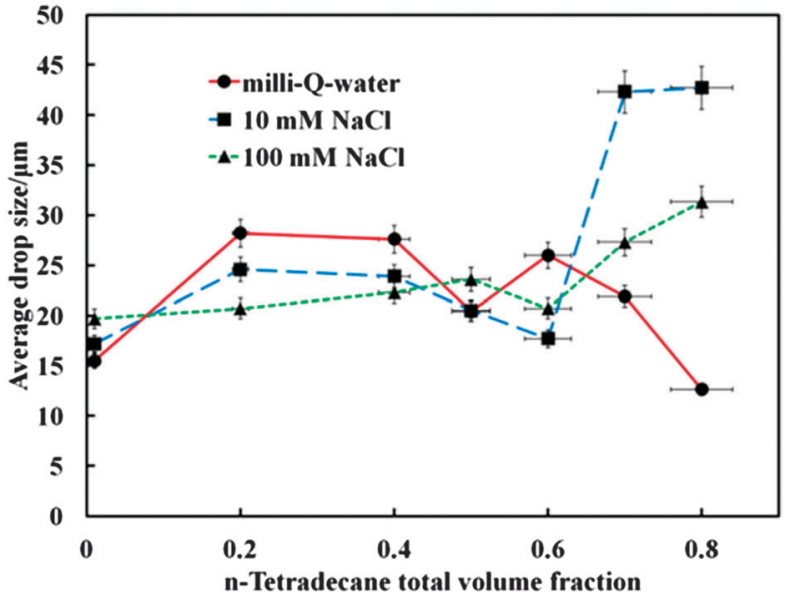

Fig. 19 The average droplet size from $\beta-C D$ stabilized emulsions prepared in the presence and absence of $\mathrm{NaCl}$ as a function of the tetradecane oil volume fraction. For each data point micrographs with concentrated droplets, more than 200 droplets were used for the measurements which included averaging of the results over multiple screenshots.

\section{Stoichiometry of the CD-tetradecane inclusion complex}

We have studied the ratio of the cyclodextrin-to-tetradecane in the inclusion complex in an attempt to characterise the way this
Table 1 Percentage compositions of carbon for pure $n$-tetradecane, pure $\alpha$-CD and pure $\beta-C D$ and the corresponding $\%$ compositions after forming inclusion complexes between CDs and tetradecane at two different oil volume fractions

\begin{tabular}{lccllllll}
\hline & & Pure & Pure & $\alpha-\mathrm{CD} / 10$ & $\alpha-\mathrm{CD} / 20$ & $\beta-\mathrm{CD} / 10$ & $\beta-\mathrm{CD} / 20$ \\
Material & $\mathrm{TD}$ & $\alpha-\mathrm{CD}$ & $\beta-\mathrm{CD}$ & $\mu \mathrm{L}$ TD & $\mu \mathrm{L}$ TD & $\mu \mathrm{L}$ TD & $\mu \mathrm{L}$ TD \\
\hline \%wt C content & 2.34 & 39.29 & 37.88 & 44.77 & 44.76 & 44.56 & 44.56 \\
Stoichiometry & & & & $6.8: 1$ & $6.8: 1$ & $5.7: 1$ & $5.7: 1$ \\
(CD:TD) & & & & & & &
\end{tabular}

complex is formed. We employed elemental analysis using a Carlo Erba EA 1108 CHN Fisons Instrument. Helium gas with a flow rate of $140 \mathrm{~mL} \mathrm{~min}^{-1}$ was used as a carrier gas (while pure oxygen flowing at $20 \mathrm{~mL} \mathrm{m^{-1 }}$ was used for combustion) for our samples of $\alpha$-CD, $\beta$-CD (crystals) and the inclusion complexes of these materials with tetradecane. The results for the carbon content in the samples presented here allowed us to estimate the number of $\alpha$-CD and $\beta$-CD molecules threaded per molecule of tetradecane (Table 1 ).

Our data show the following approximate stoichiometries of these complexes, $\alpha-\mathrm{CD}_{6.8} \mathrm{TD}_{1}$ and $\beta-\mathrm{CD}_{5.7} \mathrm{TD}_{1}$, respectively. These results suggest that the stoichiometry is independent of the volume of the oil. The maximum theoretical number of CDs per stretched length of TD with $109^{\circ}$ degree between $\mathrm{C}-\mathrm{C}-$ $\mathrm{C}$ bonds was 5.6. We propose that the CD-tetradecane inclusion complexes are formed by mobile TD molecules along CD 
nanotubes. We also checked our results using thermogravimetric analysis (TGA) under nitrogen using a Mettler TGA/DSC ${ }_{1}$ thermogravimetric analyser with STAR software operated at the heating rate of $20{ }^{\circ} \mathrm{C} \mathrm{min}{ }^{-1}$ and the weight percent of the remaining material was recorded while the furnace was heated over the temperature range from room temperature to $800{ }^{\circ} \mathrm{C}$. The nitrogen flow rate was $40 \mathrm{~mL} \mathrm{~min}^{-1}$.

\section{Conclusions}

We have studied $\alpha$-CD and $\beta$-CD stabilised emulsions formed as a result of growth and adsorption of rod-like microcrystals of CD-oil inclusion complexes at the oil-water interface. This phenomenon represents an interesting effect where the adsorption of molecularly dissolved cyclodextrins from the water to the oil-water interface leads to a Pickering emulsion stabilised by solid microparticles. We have investigated the effect of the size of $\alpha$-CD and $\beta$-CD-oil microrods, which grow in situ to stabilize the o/w emulsions. Shorter $(<10 \mu \mathrm{m})$ $\beta$-CD-tetradecane microcrystals showed a better stabilizing effect of $\mathrm{o} / \mathrm{w}$ emulsions compared to the long and rigid $\alpha$-CDtetradecane microrods ( $\gg 20 \mu \mathrm{m}$ ). We studied the effect of the tetradecane volume fraction on the stability of the tetradecanein-water Pickering emulsions. $\beta$-CD-stabilised emulsions showed better long-term stability than $\alpha$-CD stabilised emulsions due to better packing of the smaller microcrystals on the emulsion drop interface. Our findings show that only $\mathrm{o} / \mathrm{w}$ emulsions were formed in $\alpha$-CD and $\beta$-CD stabilised systems even at high volume fractions of tetradecane. However, we studied CD-stabilised emulsions with several other oils and were able to make w/o emulsions using silicone oil of high viscosity as a continuous phase. We have highlighted the importance of the size of the CD microrods/particles in relation to their ability to stabilise emulsions by Pickering stabilisation. We also investigated the effect of the presence of a salt in the aqueous phase on the emulsion stability with regards to surface charge effects but no significant influence was observed apart from emulsions with a very high oil volume fraction. Finally, we were able to produce for the first time cyclodextrinosomes by removing the oil from the CD-stabilised o/w emulsion by evaporation of the CD-stabilised emulsion and demonstrated that the obtained structures are stable upon redispersing in water. These new microcapsules are held together only by non-covalent interactions and can potentially find application as drug delivery vehicles and in the development of surfactant free formulations for cosmetics and personal care products.

\section{Acknowledgements}

B.G.M thanks Botswana College of Agriculture for financial support of this work as a part of his PhD studies. We thank Mr Tony Sinclair for the SEM samples preparation and imaging. V.N.P. appreciates support from the COST action CM1101.

\section{Notes and references}

1 M. B. Debasis Bagchi, H. Moriyama and F. Shahidi, Bio-Nanotechnology: A Revolution in Food, Biomedical and Health Sciences, Wiley-Backwell, Ed. Wiley \&, Newfoundland, 2013.

2 D. J. McClements, Curr. Opin. Colloid Interface Sci., 2012, 17, 235-245.

3 J. Frelichowska, M.-A. Bolzinger and Y. Chevalier, Colloids Surf., A, 2009, 343, 70-74.

4 I. Akartuna, A. R. Studart, E. Tervoort, U. T. Gonzenbach and L. J. Gauckler, Langmuir, 2008, 24, 7161-7168.

5 R. Aveyard, B. P. Binks and J. H. Clint, Adv. Colloid Interface Sci., 2003, 100-102, 503-546.

6 B. P. Binks and J. H. Clint, Langmuir, 2002, 18, 1270-1273.

7 B. P. Binks and S. O. Lumsdon, Phys. Chem. Chem. Phys., 1999, 1, 3007-3016.

8 M. V. Tzoumaki, T. Moschakis, V. Kiosseoglou and C. G. Biliaderis, Food Hydrocolloids, 2011, 25, 1521-1529.

9 C. P. Whitby, A. M. Djerdjev, J. K. Beattie and G. G. Warr, J. Colloid Interface Sci., 2006, 301, 342-345.

10 J. Thieme, S. Abend and G. Lagaly, Colloid Polym. Sci., 1999, 277, 257-260.

11 F. Yang, S. Liu, J. Xu, Q. Lan, F. Wei and D. Sun, J. Colloid Interface Sci., 2006, 302, 159-169.

12 V. N. Paunov, O. J. Cayre, P. F. Noble, S. D. Stoyanov, K. P. Velikov and M. Golding, J. Colloid Interface Sci., 2007, 312, 381-389.

13 E. Tervoort, A. R. Studart, C. Denier and L. J. Gauckler, RSC $A d v .$, 2012, 2, 8614-8618.

14 K. Shimada, K. Fujikawa, K. Yahara and T. Nakamura, J. Agric. Food Chem., 1992, 40, 945-948.

15 D. Duchêne, A. Bochot, S.-C. Yu, C. Pépin and M. Seiller, Int. J. Pharm., 2003, 266, 85-90.

16 C. Cheng, X.-J. Han, Z.-Q. Dong, Y. Liu, B.-J. Li and S. Zhang, Macromol. Rapid Commun., 2011, 32, 1965-1971.

17 C.-W. Tu, S.-W. Kuo and F.-C. Chang, Polymer, 2009, 50, 2958-2966.

18 A. Wu, X. Shen and Y. He, J. Colloid Interface Sci., 2006, 302, 87-94.

19 C. Lv, X. Chen, B. Jing, Y. Zhao and F. Ma, J. Colloid Interface Sci., 2010, 351, 63-68.

20 M. Inoue, K. Hashizaki, H. Taguchi and Y. Saito, J. Oleo Sci., 2009, 58, 85-90.

21 M. Inoue, K. Hashizaki, H. Taguchi and Y. Saito, J. Dispersion Sci. Technol., 2010, 31, 1648-1651.

22 A. L. Campbell, S. D. Stoyanov and V. N. Paunov, Soft Matter, 2009, 5, 1019-1023.

23 A. L. Campbell, B. L. Holt, S. D. Stoyanov and V. N. Paunov, J. Mater. Chem., 2008, 18, 4074-4078.

24 B. L. Holt, S. D. Stoyanov, E. Pelan and V. N. Paunov, J. Mater. Chem., 2010, 20, 10058-10070.

25 P. F. Noble, O. J. Cayre, R. G. Alargova, O. D. Velev and V. N. Paunov, J. Am. Chem. Soc., 2004, 126, 8092-8093.

26 O. J. Cayre, P. F. Noble and V. N. Paunov, J. Mater. Chem., 2004, 14, 3351-3355. 
27 A. L. Campbell, S. D. Stoyanov and V. N. Paunov, ChemPhysChem, 2009, 10, 2599-2602.

28 K. G. Marinova, R. G. Alargova, N. D. Denkov, O. D. Velev, D. N. Petsev, I. B. Ivanov and R. P. Borwankar, Langmuir, 1996, 12, 2045-2051.

29 B. P. Binks and S. O. Lumsdon, Langmuir, 2000, 16, 2539-2547.
30 B. M. Mathapa and V. N. Paunov, J. Mater. Chem. A, 2013, 1, 10836-10846.

31 R. G. Alargova, V. N. Paunov and O. D. Velev, Langmuir, 2006, 22, 765-774.

32 H. A. Wege, S. Kim, V. N. Paunov, Q. Zhong and O. D. Velev, Langmuir, 2008, 24, 9245-9253. 